\title{
Robótica na aprendizagem de física e matemática para alunas do ensino médio
}

\author{
Maitê Thomazi Manentti ${ }^{1,}$ Éverton Fabian Jasinski ${ }^{2}$, Tatiana Nilson dos Santos ${ }^{3}$, \\ Eliane Pozzebon ${ }^{3}$, Luciana Bolan Frigo ${ }^{3}$ \\ ${ }^{1}$ Laboratório de Tecnologias Computacionais - Universidade Federal de Santa Catarina \\ (UFSC) - Araranguá - SC - Brasil \\ ${ }^{2}$ Laboratório de Automação e Robótica Móvel - Universidade Federal de Santa Catarina \\ (UFSC) - Araranguá - SC - Brasil \\ ${ }^{3}$ Programa de Pós-Graduação em Tecnologias da Informação e Comunicação - \\ Universidade Federal de Santa Catarina (UFSC) - Araranguá - SC - Brasil

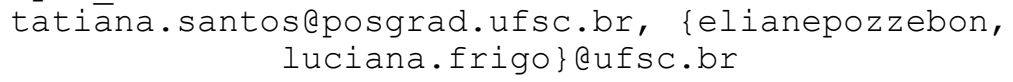

\begin{abstract}
This article presents the results of a project where robots were applied LEGO kit as a teaching tool in teaching physics and mathematics to support learning in the average level disciplines of students of High School Macário Borba located in Sombrio-SC. This course lasted 3 (three) months and the students solved practical exercises on kinematics, algebraic equations and energy conservation using robots projects that facilitate understanding. As a result realized the great motivation of students to learn in a more didactic and motivating way, considered complicated content.
\end{abstract}

Resumo. Este artigo apresenta os resultados de um projeto onde foram aplicados robôs do kit LEGO como ferramenta didática no ensino de física e matemática para auxiliar a aprendizagem nas disciplinas do nível médio das estudantes da Escola de Ensino Médio Macário Borba localizada em Sombrio-SC. Este curso teve duração de 3 (três) meses e as estudantes resolveram exercícios práticos sobre cinemática, equações algébricas e conservação de energia utilizando projetos de robôs que facilitassem o entendimento. Como resultado percebeu-se a grande motivação das estudantes ao aprenderem de uma maneira mais didática e motivadora, conteúdos considerados complicados.

\section{Introdução}

Diversas empresas têm demonstrado grande interesse no aumento de contratação de mulheres no seu quadro de pessoal. Conforme afirma Frigo, Yevseyeva e Pozzebon (2013), a multinacional Volkswagen, tem como objetivo chegar a uma proporção de $30 \%$ de mulheres graduadas em Engenharia no seu processo de recrutamento.

Mas o número de mulheres nestes cursos ainda é baixo e esta falta de incentivo começa no ensino médio, onde as estudantes sentem-se desmotivadas em estudar os 
conteúdos das disciplinas que serão base dos cursos de engenharia (como física e matemática, por exemplo), por estas tratarem de temas que são de difícil assimilação. Em virtude da abordagem técnica, o baixo número de ferramentas que auxiliem os docentes a reforçar determinados tópicos destas disciplinas é um fator impactante no processo de ensino/aprendizagem [POZZEBON e FRIGO, 2013].

Desta forma, a utilização da robótica nestas disciplinas, consideradas mais complicadas, visa instigar a curiosidade e a criatividade das estudantes para solucionarem diferentes tipos de problemas, além de proporcionar um ensino mais motivador e didático [POZZEBON e FRIGO, 2013].

O objetivo deste projeto foi estimular a formação de engenheiras no Brasil, combatendo a evasão das graduandas nos primeiros anos do curso, despertar o interesse das estudantes de ensino médio pela profissão de engenheira de computação, além de promover uma união entre as instituições públicas da região com a comunidade acadêmica.

\section{Robótica Educacional}

A robótica educacional é uma área multidisciplinar, pois engloba o conteúdo de diferentes disciplinas com o objetivo de construir robôs para desempenhar as mais variadas tarefas [NEHMZOW, 2000].

Por ser uma área que desperta bastante curiosidade, a robótica pode ser usada como ferramenta didática para auxiliar os docentes em diferentes conteúdos dependendo da disciplina a ser ensinada. Para as estudantes, a robótica é uma excelente ferramenta para exercitar a criatividade, estudar e praticar conceitos relacionados as disciplinas [NEHMZOW, 2000].

A vantagem de se construir robôs é o total conhecimento sobre todas as partes que o compõem, proporcionando ao docente a oportunidade de lançar desafios aos alunos, para que estes construam robôs, desde os modelos mais simples até os considerados mais complexos. Como por exemplo, o docente da disciplina de física pode utilizar os robôs para demonstrar na prática os conteúdos teóricos sobre os efeitos de cinemática, dinâmica, inércia, movimento retilíneos, etc [SILVA, et. al. 2008].

A complexidade inerente à robótica irá depender do grau de exploração do docente, uma vez que esta proporcionará uma visão de aprendizagem mais significativa para os alunos. Além disso, ela cria condições de discussão sobre assuntos diversificados promovendo uma interação maior entre docente e discente [POZZEBON e FRIGO, 2013].

\section{Desenvolvimento das Atividades}

O curso iniciou suas atividades em dezembro de 2014 e estendeu-se até março de 2015, foram realizadas oficinas de física e matemática com as estudantes do primeiro ano do ensino médio da Escola de Ensino Macário Borba localizada em Sombrio-SC, com cerca de 15 (quinze) meninas, para tornar as aulas divertidas e principalmente mais visuais.

O curso era constituído de uma aula, com duração média de 2 (duas) horas, realizada em um dia de aula, ou seja, de segunda a sexta-feira. Foram utilizados os kits da Lego ${ }^{\circledR}$ Mindstorm ${ }^{\circledR}$, disponibilizados pelo Laboratório de Tecnologias Computacionais - LabTeC. Esses kits consistem de várias peças que foram utilizadas para criar a estrutura de um pequeno robô. Também eram encaixados junto a essa 
estrutura motores e sensores para permitir uma maior interação entre o robô e o ambiente de atuação do mesmo.

Uma das finalidades do curso era a de expor aplicações da física e da matemática com o auxílio da robótica. Como a ementa da oficina foi compatível com o que as estudantes trabalharam em sala de aula então tivemos 3 (três) assuntos principais: i) Conceitos Básicos de Cinemática: móvel, referencial, movimento e repouso, deslocamento, velocidade média, aceleração média, funções horárias; ii) Equações algébricas: incógnitas, igualdade; iii) Conservação de Energia: energia potencial gravitacional, energia cinética, energia mecânica.

Foi elaborada uma apostila onde foram apresentados três exercícios em que as estudantes deveriam anotar os valores obtidos em cada experimento e calcular utilizando os conceitos e fórmulas, observando que o objetivo era que elas conseguissem aplicar e entender a conceituação ensinada pelo docente, com isso, comprovar a veracidade das fórmulas.

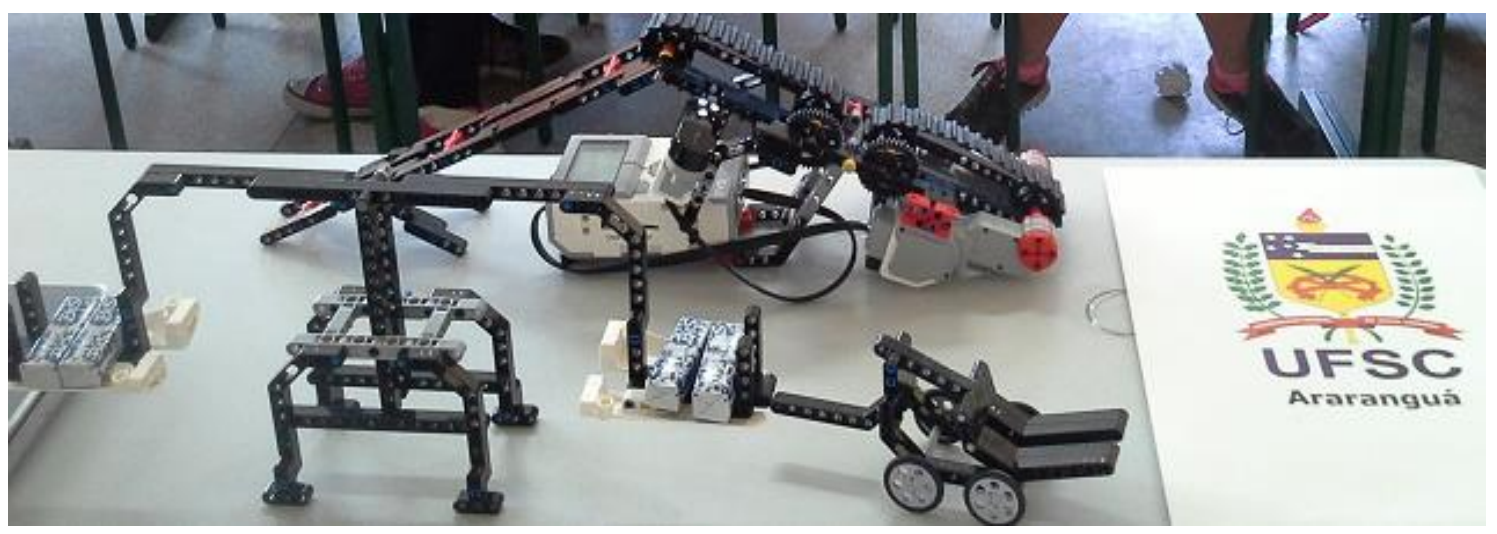

Figura 1: Balança para o experimento das equações algébricas

Para essa experiência, foi criada com os kits de robótica uma balança (Figura 1) para o experimento das equações algébricas, fazendo-se uso do chocolate para o equilíbrio da balança.

Finalizando com o entendimento do conteúdo através da associação de que uma balança pode ser uma igualdade, uma montanha-russa para a questão da conservação de energia, utilizando um motor para fazer com que a trilha de movimente e consequentemente o trem feito com o kit ganha velocidade, então a energia potencial se transforma em energia cinética e permite aos carros completarem o percurso, ou parte dele, através desta força adquirida.

A energia cinética é novamente transformada em energia potencial enquanto o trem se move novamente para o próximo pico, neste caso, há um único pico, e um carrinho para demonstrar o movimento acelerado, mudando as potências do motor, e retardado, simulando uma corrida.

Participaram do curso, exercendo a função de monitoras, estudantes do gênero feminino dos cursos de Engenharia da Computação e Tecnologias da Informação e Comunicação (UFSC - Araranguá). Esta escolha se deu, propositalmente, para incentivar ainda mais as estudantes do ensino médio, mostrando a participação das mulheres nos cursos das áreas tecnológicas. 


\section{Resultados e Discussões}

Os resultados até o momento apresentaram-se positivos; avaliados por meio de observação, notou-se o interesse das estudantes pelo curso, onde aprenderam na prática conceitos de física e matemática, até então considerados complexos auxiliados pelo artefato tecnológico (robótica).

As alunas que participaram deste projeto comentaram em depoimentos sobre a importância de realizar atividades relacionadas com o conteúdo das disciplinas de maneira mais atrativas e interativas. Quantos aos resultados, $100 \%$ das alunas interagiram rapidamente com a tecnologia, não houve resistência quanto ao aprendizado com um novo instrumento. Em torno de 35\% fizeram questionamentos pertinentes ao conteúdo e cerca de $93 \%$ relataram que gostaram do aprendizado diversificado.

Tem-se como expectativa, com a continuidade do projeto, o aumento no número de ingressantes do gênero feminino no curso de Engenharia de Computação e também em outras engenharias, pois este é o objetivo do curso, incentivá-las a ingressarem nas áreas tecnológicas.

Como resultado extra, alguns docentes de escolas que participam do Programa de Mestrado em Física da UFSC (Araranguá) se interessaram pela proposta do projeto e estão desenvolvendo suas pesquisas em novos problemas-desafios de física utilizando os robôs Lego EV3.

\section{Considerações}

A aplicação dos robôs do kit LEGO como ferramenta didática no ensino de física e matemática para auxiliar a aprendizagem nas disciplinas do nível médio poderá ser utilizada como um exemplo para outras escolas e disciplinas. Ao longo do projeto foram desenvolvidas as seguintes atividades, i) Definição dos problemas de física e matemática que foram abordados com os kits Lego; ii) Preparação do material didático que foi utilizado nas atividades; iii) Treinamento das estudantes bolsistas para o manuseio e o desenvolvimento de soluções com os kits Lego; iv) Atividades didáticas com os problemas de física e matemática; v) Preparação de relatórios e artigos científicos para posterior submissão para congressos e revistas especializadas e vi) Participação da $13^{a}$ SEPEX - Semana de Ensino, Pesquisa e Extensão da Universidade Federal de Santa Catarina, objetivando a divulgação do projeto.

\section{Referências}

Frigo, L. B.; Yevseyeva, O.; e Pozzebon, E. (2013) "El análisis de la diferencia de género en la educación. Estudio de caso en Araranguá-Brasil". In: Mundo Nuevo, Venezuela, n. 13, ano, V, p. 131-145.

Nehmzow, U. (2000) “Mobile Robotics: A Practical Introduction”. Springer, 243p.

Pozzebon, E.; e Frigo, L. B. (2013) "Robótica no processo de ensino e aprendizagem". In: International Conference on Interactive Computer Aided Blended Learning, p. 104-107.

Silva, A. F.; Agaé, A.; Gonçalves, L. M.; Guerreiro, A. M. G.; Pitta, R.; e Aranibar, D. B. (2008) "Utilização da Teoria de Vygotsky em Robótica Educativa". UFRN: Natal, 2008. Departamento de Engenharia da Computação e Automação, Universidade Federal do Rio Grande do Norte, Natal, 2008. 